\title{
NHERF1 Suppresses Lung Cancer Cell Migration by Regulation of Epithelial-Mesenchymal Transition
}

\author{
FENGLIAN YANG ${ }^{1,2}$, YANAN GU ${ }^{1,2}$, ZEHANG ZHAO ${ }^{1,2}$, JING HUANG $^{1,2}$, \\ WEN G. JIANG ${ }^{1,2,3}$ and SHAN CHENG ${ }^{1,2}$ \\ ${ }^{1}$ Department of Biochemistry and Molecular Biology, School of Basic Medical Sciences, \\ Capital Medical University, Beijing, P.R. China; \\ ${ }^{2}$ Beijing Key Laboratory of Cancer \& Metastasis Research, Capital Medical University, Beijing, P.R. China; \\ ${ }^{3}$ Cardiff China Medical Research Collaborative, \\ Cardiff University School of Medicine, Cardiff, U.K.
}

\begin{abstract}
Background/Aim: $\mathrm{Na}(+) / \mathrm{H}(+)$ exchanger regulatory factor 1 (NHERF1) has been reported to interact with many cancer-related proteins and plays an important role in cancer progression. However, little is known about the biological functions of NHERF1 in lung cancer cells. The aim of the current study was to explore whether NHERF1 is involved in transforming growth factor (TGF)- $\beta 1$-induced epithelial-mesenchymal transition (EMT) in non-small-cell lung cancer cells. Materials and Methods: The expression of NHERF1 and EMT-associated markers including E-cadherin, $N$-cadherin, snail family transcriptional repressor 1 (SNAII) and snail family transcriptional repressor $2(S L U G)$ were analyzed by reverse transcription polymerase chain reaction $(R T-P C R)$ and western blotting. The migratory properties of cells were assessed using a wound-healing assay. Results: TGF- $\beta 1$-induced a pro-migratory response in the A549 lung cancer cell line, that was consistently associated with corresponding changes in the expression levels of EMTrelated genes. The expression of NHERF1 significantly decreased in the TGF- $\beta 1$-induced A549 cells. Overexpression of NHERF1 significantly inhibited the migratory ability of cells and reversed the TGF- $\beta 1$-induced mesenchymal phenotype of A549 cells. Conclusion: These data showed an important role of NHERF1 in the EMT of non-small-cell lung cancer cells, as well as migration.
\end{abstract}

Lung cancer is one of the most prevalent and lethal cancers worldwide (1). Non-small-cell lung cancer (NSCLC)

Correspondence to: Shan Cheng, Department of Biochemistry and Molecular Biology, School of Basic Medical Sciences, Capital Medical University, Beijing 100069, P.R. China. Tel: +86 1083950184, e-mail: chengs@ccmu.edu.cn

Key Words: NHERF1, lung cancer, EMT, migration. accounts for approximately $80-85 \%$ of all lung cancers (1, 2). Successful treatment of this disease depends today on early diagnosis followed by surgical resection. It is difficult to reach this goal, although various new diagnostic and therapeutic methods have been developed. The prognosis of NSCLC is poor and it is estimated that the 5-year survival rate for NSCLC is less than 15\% (3,4). Thus, more sensitive and specific approaches need to be established. Identifying and characterizing molecular mechanisms that are relative to lung cancer may allow for identification of diagnostic and prognostic markers, as well as candidate therapeutic targets. $\mathrm{Na}^{+} / \mathrm{H}^{+}$exchanger regulatory factor 1 (NHERF1) or ezrinradixin-moesin (ERM) binding phosphoprotein of $50 \mathrm{kDa}$ (EBP50) plays a great role in ion transport, signal transduction and has a close relation to human cancers (5). NHERF1 was initially recognized as a scaffolding protein that can mediate specific protein-protein interactions (1). NHERF1 has been shown to regulate several G proteincoupled receptors, including receptors for parathyroid hormone, K-opioid, and $\beta 2$-adrenergic receptors (2). NHERF1 has also been reported to interact with specific growth factor receptors such as the epidermal growth factor receptor (8-10), and platelet-derived growth factor receptor $(11,12)$ and to modulate mitogenic signaling by these receptor tyrosine kinases. NHERF1 is involved in tumorigenesis and is an important player in cancer progression. Previous studies have shown NHERF1 to be upregulated in tumor tissue relative to its corresponding normal tissue in breast cancer (3), schwannoma, hepatocellular carcinomas (14), and malignant gliomas (4). Other studies report NHERF1 is a tumor suppressor (5). It was reported that intragenic mutation of the NHERF1 gene accompanied by loss of heterozygosity (LOH) occurs in 3\% (3/85) of breast cancer cell lines and primary breast tumors (6). The human NHERF1 gene is located on chromosome 17q25.1, a region that is frequently mutated in human breast and 
ovarian cancers (GenBank accession \#NM_004252) $(18,19)$. In lung cancer, only a recent report showed, cytoplasmic and nuclear NHERF1 expression was significantly higher than membranous expression in fine needle aspirates of cytology and surgical NSCLC samples, suggesting that NHERF1 could contribute to lung carcinogenesis (7). However, the function of NHERF1 in lung cancer cells has not been described.

In the present study, we found that transforming growth factor (TGF)- $\beta 1$ can inhibit NHERF1 expression in nonsmall-cell lung cancer cells. Ectopic expression of NHERF1 inhibited the acquisition of epithelial mesenchymal transition (EMT) phenotypic features and migratory properties. These findings indicate that NHERF1 could be involved in TGF$\beta 1$-induced EMT in non-small-cell lung cancer cells and regulate the malignant phenotypes of lung cancer cells by the modulation of EMT.

\section{Materials and Methods}

The dataset collection. The gene expression profiling of NSCLC cell lines upon TGF- $\beta 1$-induced EMT was downloaded from the GEO. The datasets GSE49644 consisted of 3 TGF- $\beta 1$-induced lung cancer cell lines (A549, HCC827, H358) and its parental cells.

Expression vectors and small interfering RNAs. The 3flag-tagged NHERF1 construct was cloned by our laboratory previously (8). Small interfering RNA (siRNA) duplexes directed against NHERF1 (siNHERF1-1: 5-GCUAUGGCUUCAACCUGCATT-3; siNHERF12: 5-GAAGGAGAACAGUCGUGAATT-3) and the scrambled control RNA (5-UUCUUCGAACGUGUCACGUTT-3) were synthesized by Gene-Pharma (Su Zhou, China).

Cell culture and transfection. The human lung cancer cell line, A549, was obtained from American Type Culture Collection (ATCC, Manassas, VA, USA). Cells were maintained in Dulbecco's modified Eagle medium (DMEM) supplemented with $10 \%$ fetal calf serum, penicillin and streptomycin (Gibco BRC, Paisley, Scotland) and were cultured at $37^{\circ} \mathrm{C}$ in a $5 \% \mathrm{CO}_{2}, 95 \%$ humidified atmosphere. Cells were transiently transfected with Flag-NHERF1 plasmid or NHERF1-siRNA respectively by using Lipofectamine ${ }^{\circledR} 2000$ Transfection Reagent (Invitrogen, Paisley, Scotland, UK).

$R N A$ preparation and reverse transcription polymerase chain reaction. RNA extraction and reverse transcription polymerase chain reaction (RT-PCR) were performed as described previously (9). Conditions for PCR were $10 \mathrm{~s}$ at $95^{\circ} \mathrm{C}$ for denaturation, $20 \mathrm{~s}$ at $55^{\circ} \mathrm{C}$ for annealing and $30 \mathrm{~s}$ at $72^{\circ} \mathrm{C}$ for elongation ( 35 cycles). RT-PCR primers were as follows: NHERF1 sense: 5-AGGGAAA CTGACGAGTTCTT-3; antisense: 5-ACTGAACCTGACCGTACA TTCACGACTGTTCT CCTT-3; E-cadherin sense: 5-TGCCCAGAA AATGAAAAAGG-3; antisense: 5-GTGTATGTGGCAATGCGTTC-3; N-cadherin sense: 5GACAATGCCCCTCAAGTGTT-3; antisense: 5-CCATTAAGCCG AGTGATGGT-3; snail family transcriptional repressor 2 (SLUG) sense: 5-TGATGAAGAGGA AAGACTACAG-3; antisense: 5GCTCACATATTCCTTGTCAC AG-3; snail family transcriptional repressor 1 (SNAI1) sense: 5-TACAGCGAGCTGCAGGACTCTA AT-3; antisense: 5-AGGA CAGAGTCCCAGATGAGCA TT-3;
GAPDH sense: 5-GGGAAG GTGAAGGTCGGAGT-3; antisense: 5TTGAGGTCAATGAAGG GGTCA-3.

Western blotting. The protein expression was assessed in the human lung cancer cell line lysates through standard sodium dodecyl sulfate-polyacrylamide gel electrophoresis (SDS-PAGE) and western blotting analysis. Glyceraldehyde-3-phosphate dehydrogenase (GAPDH) expression was used as an internal control. AntiNHERF1 was purchased from Becton, Dickinson and Company (Franklin, USA). SLUG, and GAPDH antibodies were purchased from Santa Cruz (California, USA). E-Cadherin, N-Cadherin and SNAI1 antibodies were from Abcam (Cambridge, UK). Protein expression was assessed and quantified using Image $\mathbf{J} 2 \times$ analysis software (Rawak Software, Inc. Germany).

Wound-healing assay. The migratory properties of cells were assessed using a wound-healing assay. Cells were seeded at a density of $1.5 \times 10^{6}$ cells/well into a 6 -well plate and allowed to reach confluence. The layer of cells was then scraped with a fine gauge needle to create a wound of approximately 1,500 $\mu \mathrm{m}$. Images of the wound were recorded under a phase contrast microscope at different times $(0,24 \mathrm{~h})$. Wound closure/cell migration was evaluated with motion analysis and line morphometry software (Image J 2x).

Statistical analysis. SPSS version 16.0 (SPSS, Inc., Chicago, IL, USA) was used for statistical analyses. The 2-sample $t$-test was used for normally distributed data. Differences were considered statistically significant at $p<0.05$.

\section{Results}

NHERF1 down-regulation correlated with TGF- $\beta 1$-induced EMT in lung cancer cells. To identify genes which are differentially expressed in lung cancer cells, we compared the gene expression profiles of TGF- $\beta 1$-treated lung cancer cells and their parental cells through a GEO dataset (GEO number: GSE49644). E-cadherin gene, the typical EMT molecular marker, was significantly down-regulated in TGF$\beta 1$-treated lung cancer cell lines (A549, HCC827, H358). Accordingly, five other typical EMT molecular markers (SNAI1, SLUG, ZEB1, Fibronectin, Vimentin) were upregulated in the TGF- $\beta 1$-induced EMT-cells. Interestingly, NHERF1 exhibited a significant decrease in transcriptional level in the EMT lung cancer cells (A549, HCC827, H358), compared to untreated parental cells (Figure 1A). These results indicated that NHERF1 could play an important role in the EMT of lung cancer.

To confirm these findings, we treated A549 with TGF- $\beta 1$. A549 cells cultured in the absence of TGF- $\beta 1$ and it was found that cells maintained the classic cobblestone epithelial morphology and growth pattern, but after treatment with 5 $\mathrm{ng} / \mathrm{ml}$ TGF- $\beta 1$ for $24 \mathrm{~h}$, the cells showed a more fibroblastlike morphology (Figure 1B). Following stimulation with TGF- $\beta 1$ ( $5 \mathrm{ng} / \mathrm{ml})$ for $24 \mathrm{~h}$, we tested the levels of expression of four typical molecular markers for A549 cells using RT-PCR and western blotting. Results showed that E- 


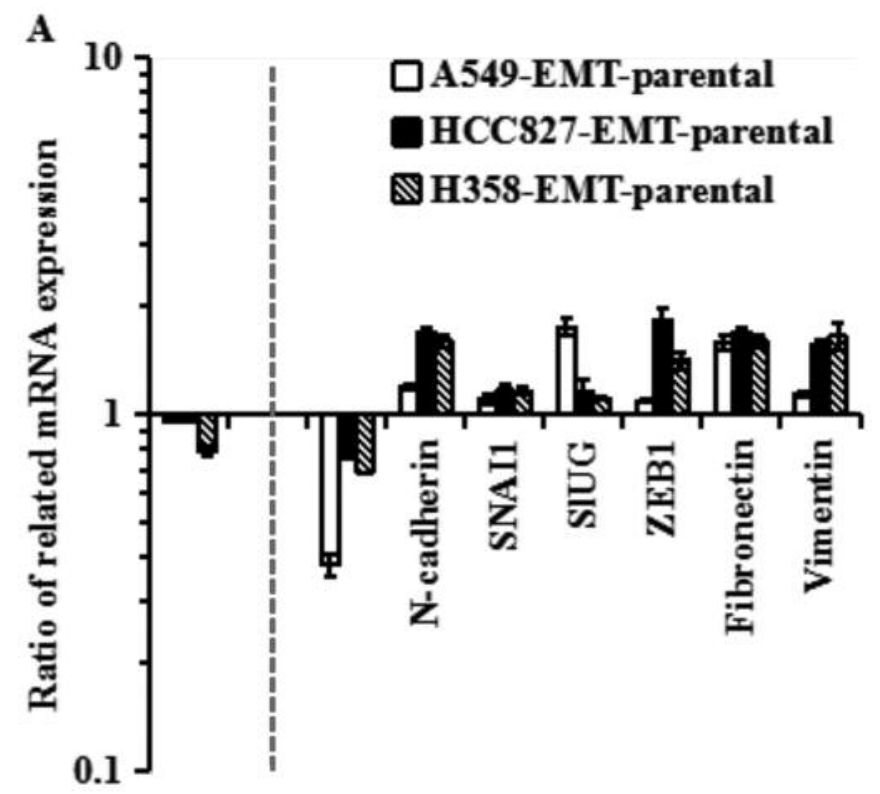

B
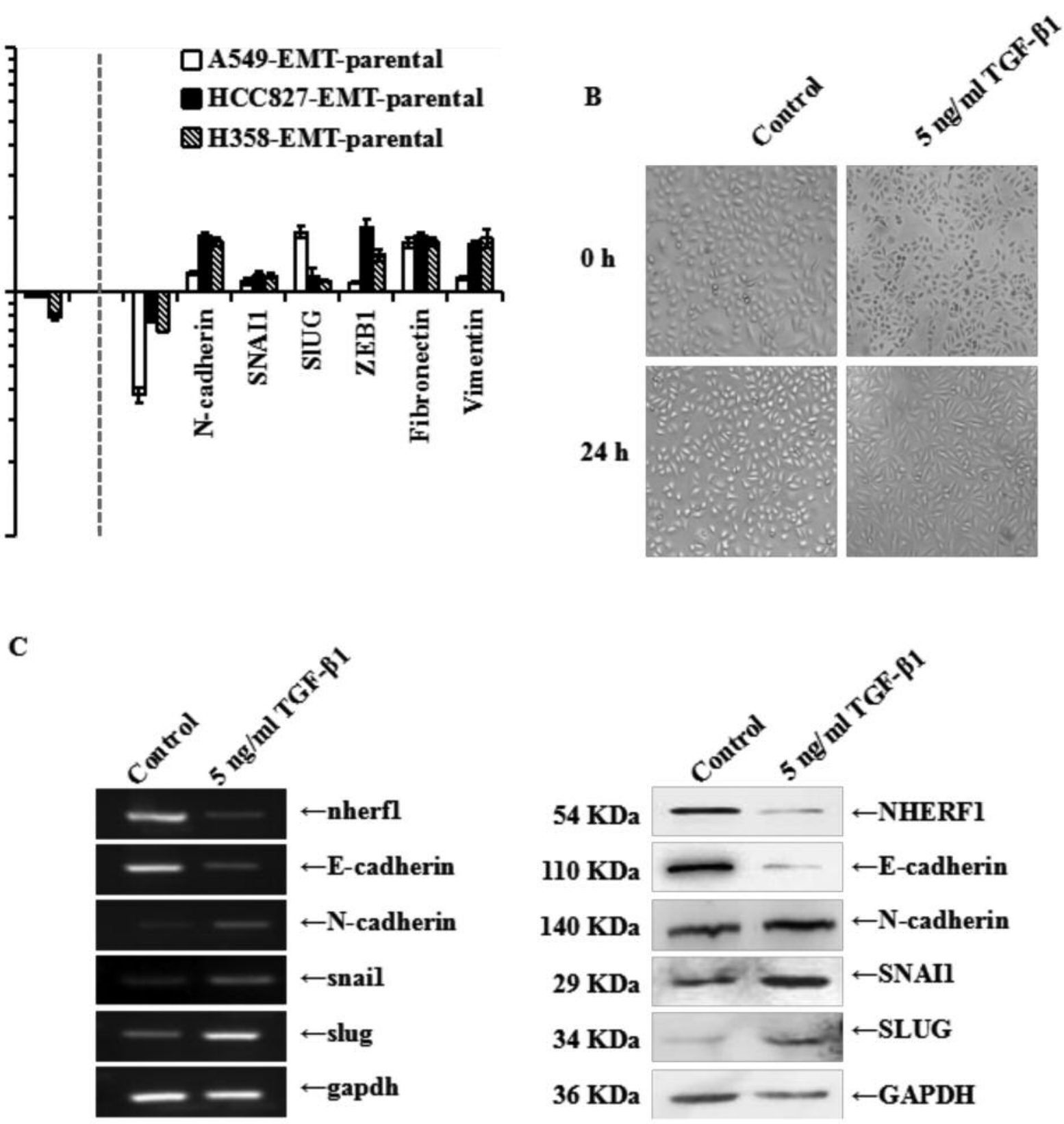

Figure 1. $\mathrm{Na}^{+} / \mathrm{H}^{+}$exchanger regulatory factor 1 (NHERF1) down-regulation correlated with transforming growth factor (TGF)- $\beta 1$-induced epithelial-mesenchymal transition (EMT) in lung cancer cells. (A) EMT markers and NHERF1 mRNA levels of lung cells A549, HCC827 and H358 were obtained from GSE database (GEO number: GSE49644). The results represent mean values $\pm S D$ of three independent experiments. (B) Morphology of A549 cells cultured with or without $5 \mathrm{ng} / \mathrm{ml}$ TGF- $\beta 1$ for $24 \mathrm{~h}$. (C) The expression of NHERF1 and EMT typical markers (E-cadherin, $N$-cadherin, SLUG, and SNAI1) were detected by reverse transcription polymerase chain reaction (RT-PCR) (left) and western blotting (right).

cadherin was markedly down-regulated, and the markers, Ncadherin, SLUG and SNAI1 were markedly up-regulated compared to the untreated A549 parental cells (Figure 1C). Moreover, the significant decline in NHERF1 expression was confirmed in the TGF- $\beta 1$-treated A549 cells (Figure 1C).
Ectopic expression of NHERF1 inhibited the acquisition of EMT phenotypic features in A549 cells after stimulation by $T G F-\beta 1$. To further investigate how TGF- $\beta 1$ induces A549 cell EMT, we focused on the role of NHERF1 in this transition. A549 cells displayed a more fibroblast-like 
A

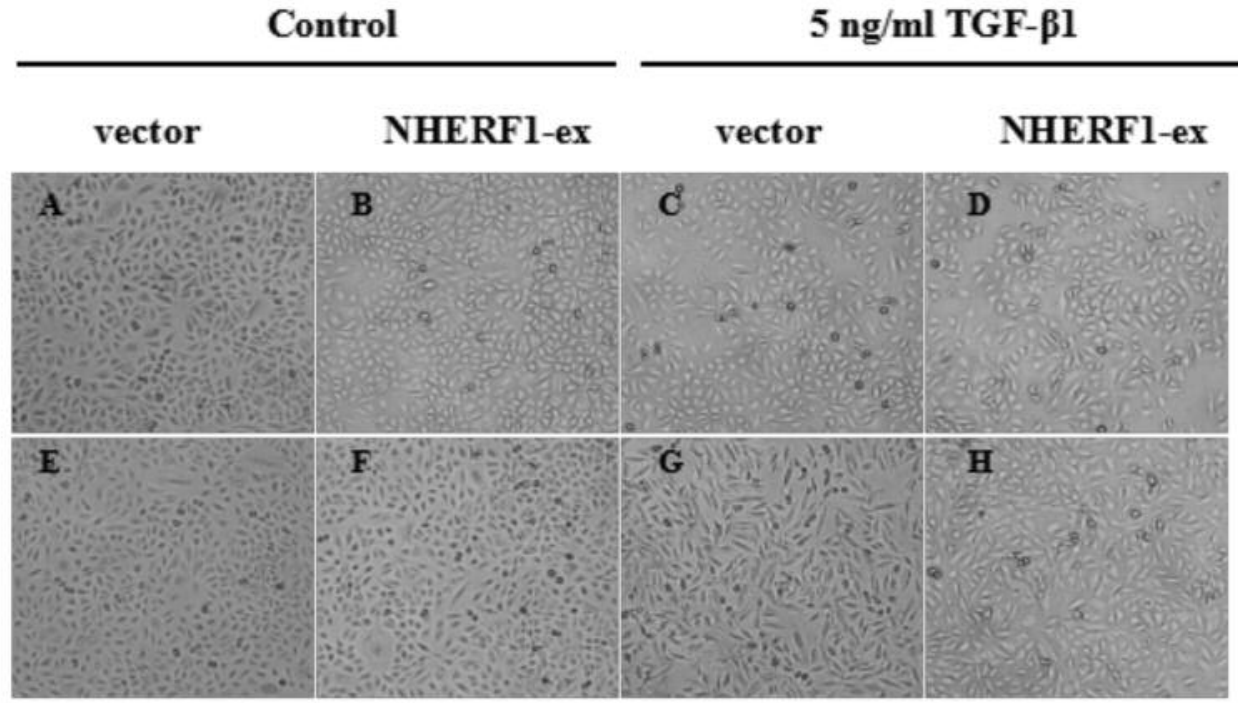

B
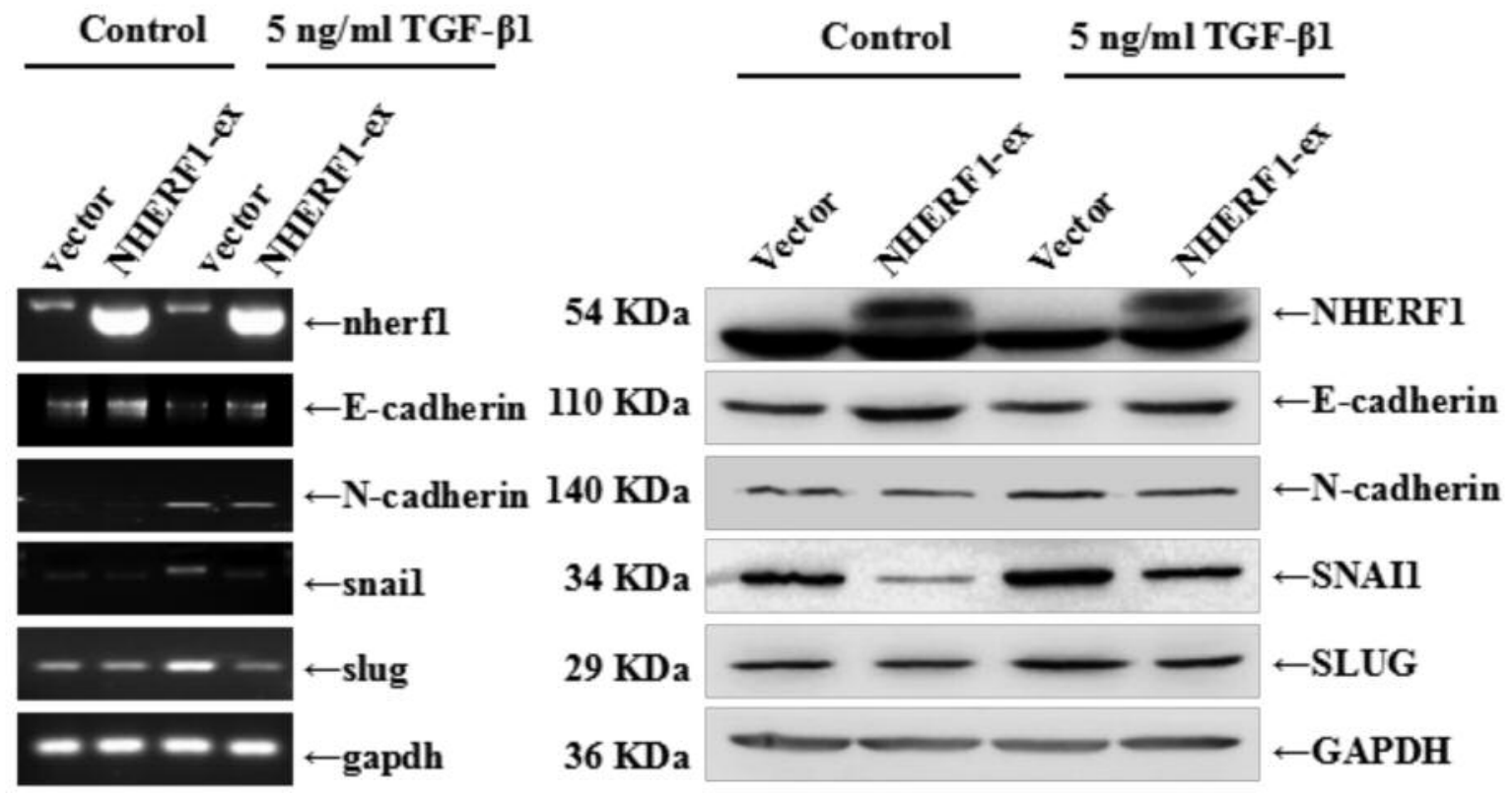

Figure 2. Ectopic overexpression of NHERF1 inhibited the acquisition of EMT phenotypic features in A549 cells after stimulation by TGF- $\beta 1$. (A) Morphology of A549 cells, transfected with NHERF1 expression plasmid or vector, with or without the treatment with $5 \mathrm{ng} / \mathrm{ml}$ TGF- $\beta 1$ for $24 \mathrm{~h}$. (B) The expression of NHERFI and EMT typical markers (E-cadherin, N-cadherin, SLUG, and SNAI1) were detected by RT-PCR (left) and western blotting (right).

morphology after treatment of $5 \mathrm{ng} / \mathrm{ml}$ TGF- $\beta 1$ for $24 \mathrm{~h}$ (Figure 2A). While, overexpression of NHERF1 (Figure 2B) inhibited the cellular morphological changes induced by TGF- $\beta 1$ (Figure 2 A). TGF- $\beta 1$-stimulated A549 lung cancer cells displayed the corresponding changes in the expression levels of EMT-related genes including the down-regulation of E-cadherin and up-regulation of $\mathrm{N}$ - cadherin, SLUG and SNAI1 (Figure 2B). While overexpression of NHERF1 reversed the TGF- $\beta 1$-induced down-regulation of E-cadherin and up-regulation of $\mathrm{N}$ cadherin, SLUG and SNAI1 compared to control cells transfected with vector (Figure 2B). These results indicated that NHERF1 protein is possibly involved in regulating TGF- $\beta 1$ induced EMT process. 


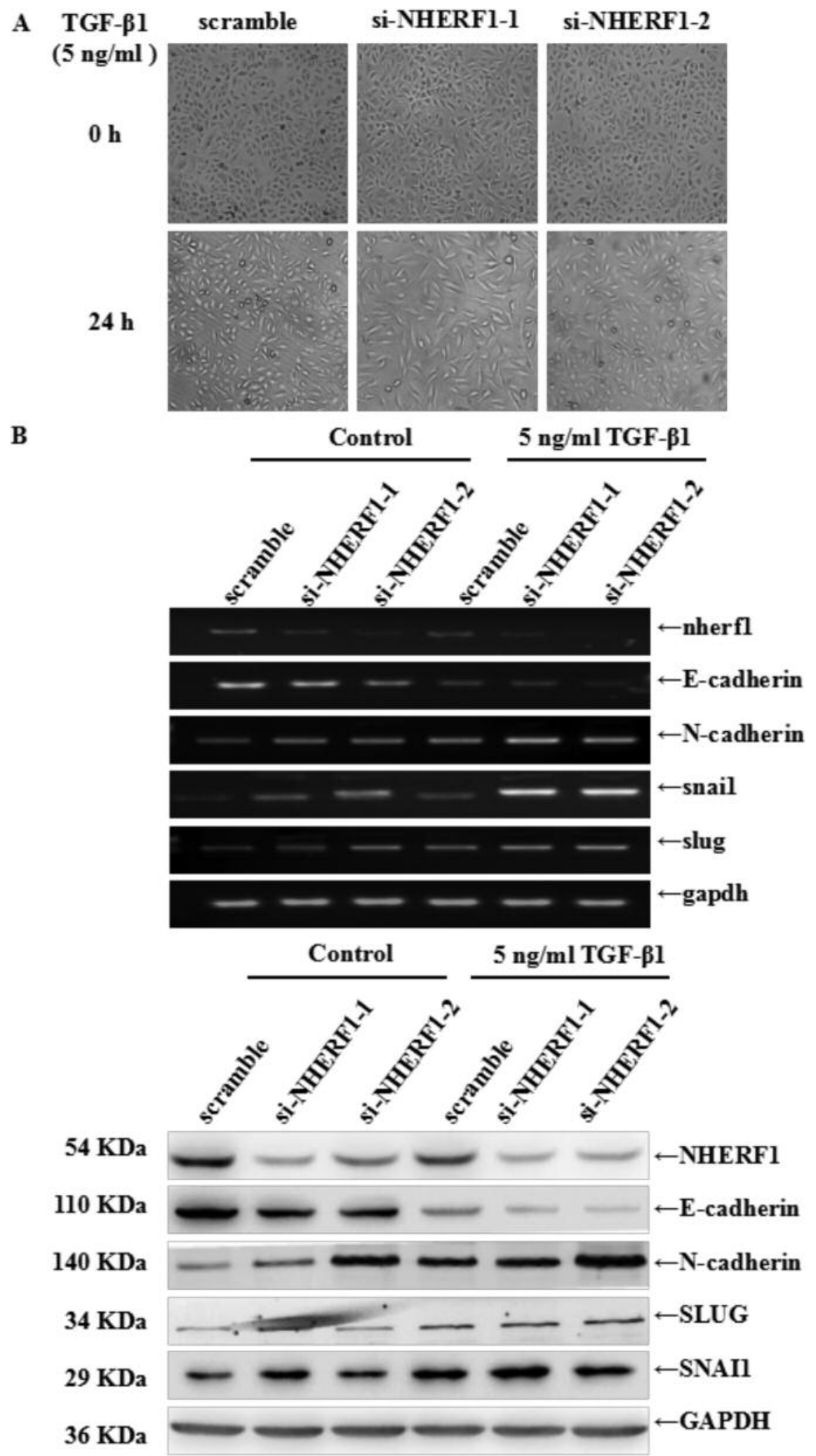

Figure 3. NHERF1 knockdown promoted the EMT of A549 cells after stimulation with TGF- $\beta 1$. (A) Morphology of A549 cells, transfected with NHERF 1 targeting SiRNA or scramble RNA, before and after the treatment with $5 \mathrm{ng} / \mathrm{ml} T \mathrm{TFF}$ - $\beta 1$ for $24 \mathrm{~h}$. (B) The expression of NHERF1 and EMT typical markers (E-cadherin, N-cadherin, SLUG, and SNAI1) were detected by RT-PCR (upper) and western blotting (lower). 
A

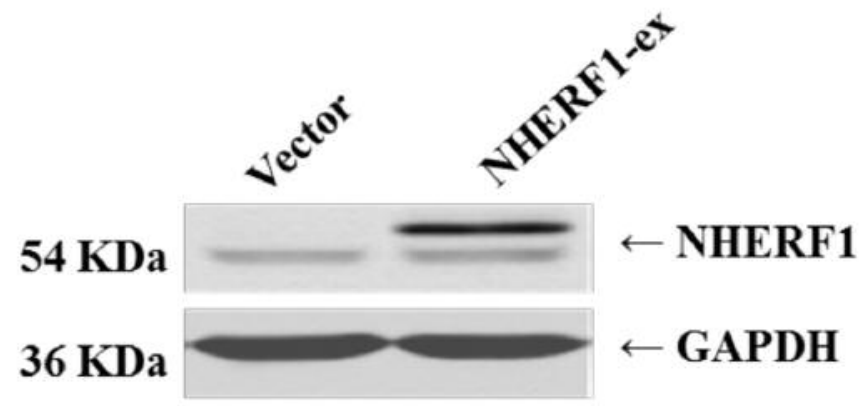

B

Control

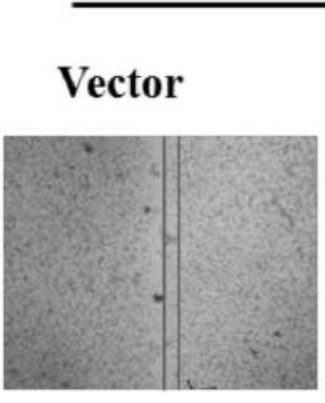

NHERF1-ex

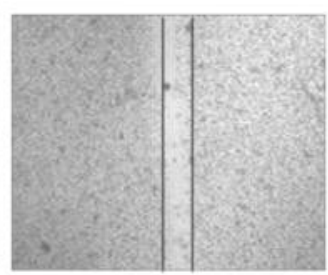

$5 \mathrm{ng} / \mathrm{ml}$ TGF- $\beta 1$

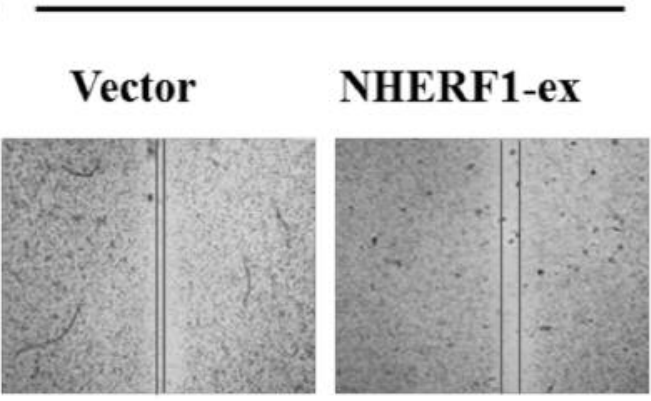

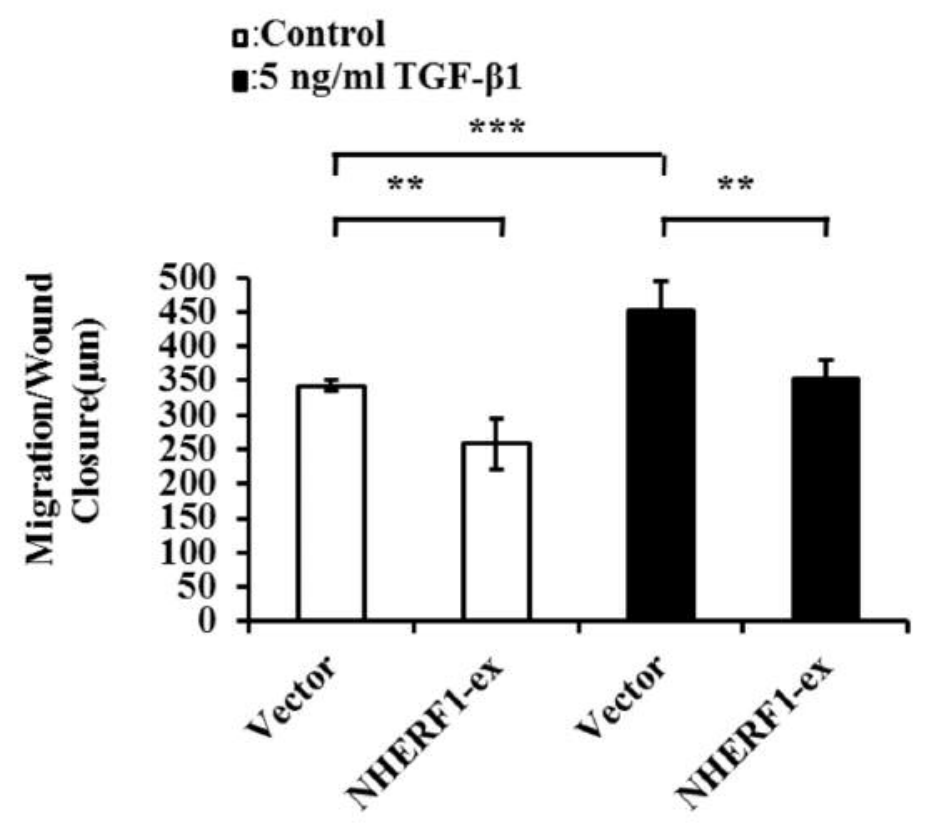

Figure 4. NHERF1 significantly suppressed TGF- $\beta 1$-induced migration in A549 cells. (A) Validation of ectopic overexpression of NHERF1 in A549 cells by western blotting. (B) NHERF1 overexpression inhibited TGF- $\beta 1$-induced cell migration in A549 cells. The results represent mean values $\pm S D$ of three independent experiments. $* p<0.05, * * p<0.01, * * * p<0.001$.

NHERF1 knockdown promoted the EMT of A549 cells after stimulation with TGF- $\beta 1$. The expression level of NHERF1 was markedly reduced in the NHERF1-knockdown A549 cells (Figure 3B). Knockdown of NHERF1 promoted the cellular morphological changes from classic cobblestone epithelial morphology to a more fibroblast-like morphology induced by TGF- $\beta 1$ (Figure 3A). Accordingly, knockdown of NHERF1 potentiated the changes in the expression levels 
A

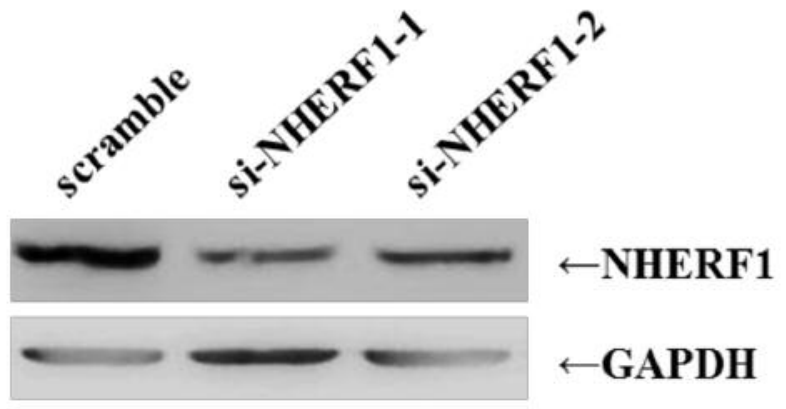

B

\section{Control} 5 ng/ml TGF- $\beta 1$
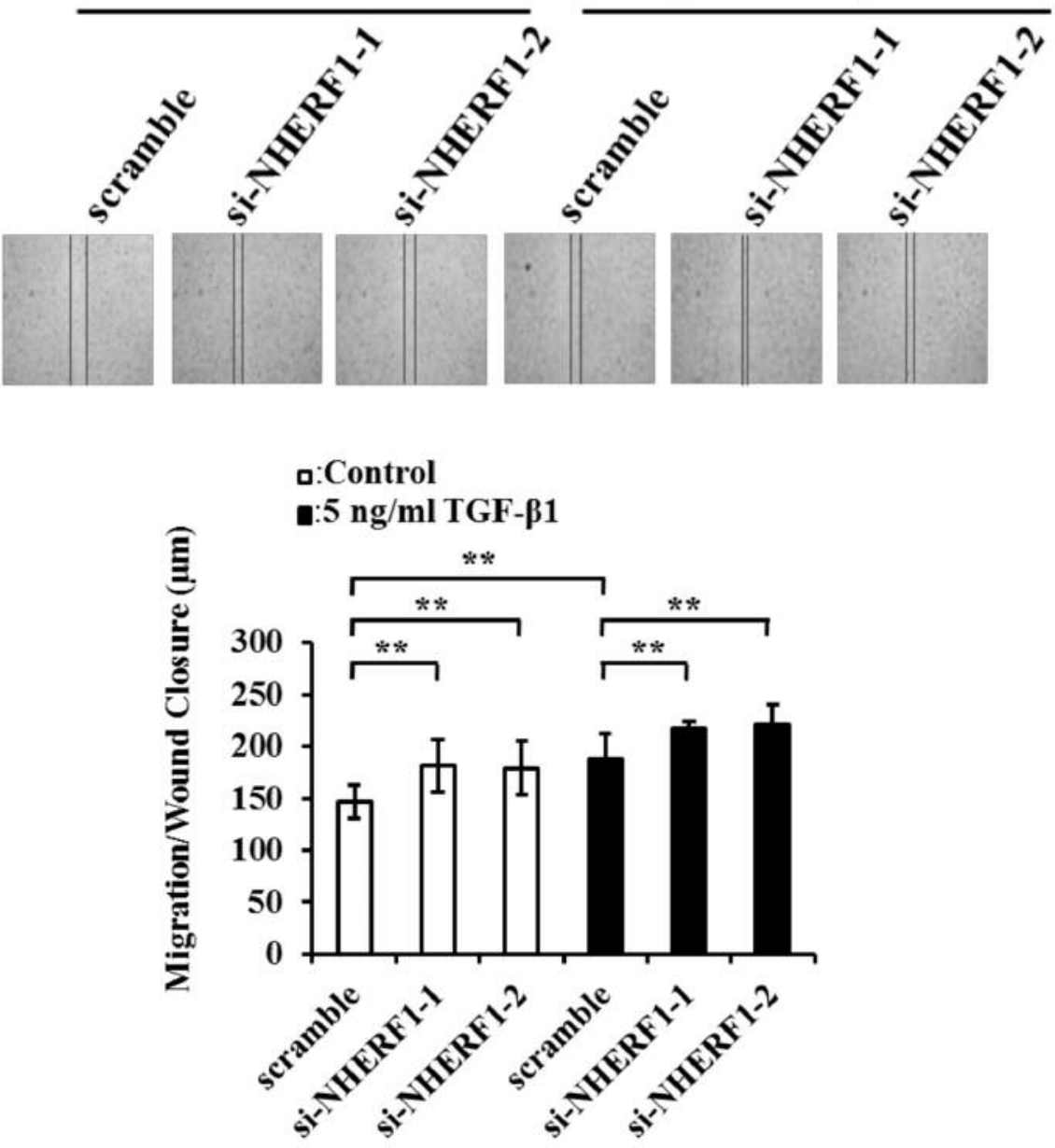

Figure 5. Migration capability of A549 cells was enhanced after knockdown of NHERF1 in A549 cells. (A) Knockdown of NHERF1 in A549 cells as shown by western blotting. (B) NHERF1 knockdown significantly promoted the migration capability in TGF- $\beta 1$-induced A549 cells. The results represent mean values $\pm S D$ of three independent experiments. $* p<0.05, * * p<0.01, * * * p<0.001$.

of EMT-related genes induced by TGF- $\beta 1$ including the down-regulation of E-cadherin and the up-regulation of $\mathrm{N}$ cadherin, SLUG and SNAI1, compared with the control cells transfected with scrambled siRNA (Figure 3B).
Overexpression of NHERF1 significantly suppressed TGF$\beta 1$-induced migration of A549 cells. Studies have demonstrated that tumor cells show enhanced migration capability following EMT. In this study, we compared the 
migration capability of A549 cells transfected with NHERF1 expression plasmid or the vector before and after exposure to TGF- $\beta 1$ using a wound healing assay. After exposure to TGF- $\beta 1(5 \mathrm{ng} / \mathrm{ml})$ for $24 \mathrm{~h}$, the A549-EMT cells exhibited increased migration capability in comparison with A549 parental cells $(p<0.01)$. Moreover, overexpression of NHERF1 significantly suppressed the migration capability both of A549 and A549 parental cells (Figure 4). The results showed that the A549 cells have a greater capacity to migrate while NHERF1 expression significantly inhibited the TGF- $\beta 1$-induced cell migration in A549 cells, suggesting that NHERF1 could inhibit the migration capability in non-small cell lung cancer cells through the regulation of EMT.

Migration capability of A549 cells was enhanced after the knockdown of NHERF1. Compared to control groups, TGF- $\beta 1$ significantly increased the migratory ability of A549 cells. Knockdown of NHERF1 remarkably promoted the migratory ability both in A549 and parental cells (Figure 5) $(p<0.01)$. These results confirmed the effects of NHERF1 on the migration capability in nonsmall cell lung cancer cells which could be through the regulation of EMT.

\section{Discussion}

Lung cancer emerges as the most common malignancy worldwide (10), ranking first in cancer mortality and incidence. Although chemotherapy has improved the survival of patients with NSCLC, most patients die because of cancer invasion and metastasis (11). EMT plays an important role in invasion and metastasis of lung cancers $(24,25)$. There is evidence to suggest that EMT shortens overall survival of the patients (26).

The developmental program of EMT can be activated in tumor cells by TGF- $\beta 1(27,28)$. EMT leads to loss of cell adhesion and increases motility of cells (29). EMT can be detected by down-regulation of epithelial makers such as Ecadherin and gain of mesenchymal makers such as vimentin and fibronectin (12). The expression of a large number of genes is changed during this process. The analysis of gene expression profiles through a GEO dataset (GEO number: GSE49644) showed that NHERF1 was significantly decreased at the transcriptional level in the EMT lung cancer cells (A549, HCC827, H358). The results were confirmed by the detection of the protein expression levels in the TGF- $\beta 1$ induced A549-EMT cells. These results suggested that NHERF1 could play an important role in the EMT in lung cancer. Further research showed ectopic expression of NHERF1 inhibited the acquisition of EMT phenotypic features and migration capability in A549 cells following stimulation by TGF- $\beta 1$. While the knockdown of NHERF1 promoted EMT and the migratory capability of A549-EMT cells. These results suggested NHERF1 could inhibit the malignant phenotypes including the migratory ability of lung cancer cells through the regulation of EMT, which implicated a role for NHERF1 in lung cancer.

NHERF1 possesses two PSD-95/Dlg/Zonula occludens1(PDZ) protein-interacting domains and a C-terminal binding domain for ERM proteins that interact with the actin cytoskeleton (31). Through its binding domains, NHERF1 exerts anchoring functions at the interface of the plasma membrane and cytoplasm. NHERF1 has emerged as a major regulator of cancer signaling networks by assembling cancer-related proteins. It has been reported that advanced colorectal cancer exhibited a higher NHERF1 expression in tumor cell cytoplasm and nucleus than the membranes (32). Herein we provide evidence to suggest a negative role of NHERF1 in the aggressiveness of lung cancer cells. There seems to be some contradiction between the clinical perspectives and results from cell assays. However, it has been showed that the PDZ-scaffold NHERF1 carries either anti-tumor or pro-tumor functions, two antinomic functions dictated by NHERF1 expression or subcellular localization (1). The dual function of NHERF1 encompasses the regulation of several major signaling pathways engaged in cancer, including the receptor tyrosine kinases platelet-derived growth factor receptor (PDGFR) and epidermal growth factor receptor (EGFR), phosphatidylinositol 3 kinase (PI3K)/ phosphate and tensin homolog (PTEN)/protein kinase B (AKT) and $\mathrm{Wnt} / \beta$-catenin pathways $(6,33)$. Moreover, the existence of compensatory expression mechanisms has been proven for many anti-oncogenes. It has been suggested that a dynamic interplay between NHERF1 and vascular endothelial growth factor receptor 2 (VEGFR2) signaling exists in colon cancer cells (8). Hypoxia conditions induced NHERF1 expression by the activation of VEGF signaling, NHERF1 in turn inhibited the activation of VEGFR2 signal pathway, resulting in the reduction of the migration and invasion of colon cancer cells. Overall, NHERF1 downstream signaling pathways involved in the underlying activation mechanisms are indeed complicated and require further thorough investigation, especially in lung cancer.

In conclusion, our study demonstrated that reduced expression of NHERF1 was correlated with TGF- $\beta 1$ induced EMT in lung cancer cells. Ectopic expression of NHERF1 inhibited the acquisition of EMT phenotypic features and migration capability in A549 cells after stimulation by TGF- $\beta 1$. These results suggest NHERF1 could inhibit malignant phenotypes, including the migratory ability of lung cancer cells, through regulation of EMT, which indicates that NHERF1 could play an important role in the EMT of lung cancer. 


\section{Acknowledgements}

This work was supported by National Natural Science Foundation of the People's Republic of China (grant No. 81572704, 81672726). The Authors would also like to thank Cancer Research Wales and the Albert Hung Foundation for their support.

\section{References}

1 Esposito V, Baldi A, Tonini G, Vincenzi B, Santini M, Ambrogi V, Mineo TC, Persichetti P, Liuzzi G, Montesarchio V, Wolner E, Baldi $\mathrm{F}$ and Groeger AM: Analysis of cell cycle regulator proteins in non-small cell lung cancer. Journal of clinical pathology 57: 58-63, 2004.

2 Wang W, Sheng W, Yu C, Cao J, Zhou J, Wu J, Zhang H and Zhang S: REV3L modulates cisplatin sensitivity of non-small cell lung cancer H1299 cells. Oncol Rep 34: 1460-1468, 2015.

3 Moran C: Importance of molecular features of non-small cell lung cancer for choice of treatment. Am J Pathol 178: 19401948, 2011.

4 Molina JR, Yang P, Cassivi SD, Schild SE and Adjei AA: Nonsmall cell lung cancer: epidemiology, risk factors, treatment, and survivorship. Mayo Clin Proc 83: 584-594, 2008.

5 Li JG, Chen C and Liu-Chen LY: Ezrin-radixin-moesin-binding phosphoprotein-50/Na+/H+ exchanger regulatory factor (EBP50/NHERF) blocks U50,488H-induced down-regulation of the human kappa opioid receptor by enhancing its recycling rate. J Biol Chem 277: 27545-27552, 2002.

6 Vaquero J, Nguyen Ho-Bouldoires TH, Claperon A and Fouassier L: Role of the PDZ-scaffold protein NHERF1/EBP50 in cancer biology: from signaling regulation to clinical relevance. Oncogene 36: 3067-3079, 2017.

7 Weinman EJ, Hall RA, Friedman PA, Liu-Chen LY and Shenolikar S: The association of NHERF adaptor proteins with $\mathrm{g}$ protein-coupled receptors and receptor tyrosine kinases. Annu Rev Physiol 68: 491-505, 2006

8 Lazar CS, Cresson CM, Lauffenburger DA and Gill GN: The $\mathrm{Na}^{+} / \mathrm{H}^{+}$exchanger regulatory factor stabilizes epidermal growth factor receptors at the cell surface. Mol Biol Cell 15: 5470-5480, 2004.

9 Bellizzi A, Greco MR, Rubino R, Paradiso A, Forciniti S, Zeeberg K, Cardone RA and Reshkin SJ: The scaffolding protein NHERF1 sensitizes EGFR-dependent tumor growth, motility and invadopodia function to gefitinib treatment in breast cancer cells. Int J Oncol 46: 1214-1224, 2015.

10 Cheng S, Li Y, Yang Y, Feng D, Yang L, Ma Q, Zheng S, Meng $\mathrm{R}$, Wang S, Wang S, Jiang WG and He J: Breast cancer-derived K172N, D301V mutations abolish $\mathrm{Na}^{+} / \mathrm{H}^{+}$exchanger regulatory factor 1 inhibition of platelet-derived growth factor receptor signaling. FEBS Lett 587: 3289-3295, 2013

11 James MF, Beauchamp RL, Manchanda N, Kazlauskas A and Ramesh V: A NHERF binding site links the betaPDGFR to the cytoskeleton and regulates cell spreading and migration. J Cell Sci 117: 2951-2961, 2004.

12 Maudsley S, Zamah AM, Rahman N, Blitzer JT, Luttrell LM, Lefkowitz RJ and Hall RA: Platelet-derived growth factor receptor association with $\mathrm{Na}(+) / \mathrm{H}(+)$ exchanger regulatory factor potentiates receptor activity. Mol Cell Biol 20: 8352$8363,2000$.
13 Meng R, Qin Q, Xiong Y, Wang Y, Zheng J, Zhao Y, Tao T, Wang Q, Liu H, Wang S, Jiang WG and He J: NHERF1, a novel GPER associated protein, increases stability and activation of GPER in ER-positive breast cancer. Oncotarget 7: 54983-54997, 2016.

14 Shibata T, Chuma M, Kokubu A, Sakamoto M and Hirohashi S: EBP50, a beta-catenin-associating protein, enhances Wnt signaling and is over-expressed in hepatocellular carcinoma. Hepatology 38: 178-186, 2003.

15 Molina JR, Agarwal NK, Morales FC, Hayashi Y, Aldape KD, Cote $\mathrm{G}$ and Georgescu MM: PTEN, NHERF1 and PHLPP form a tumor suppressor network that is disabled in glioblastoma. Oncogene 31: 1264-1274, 2012.

16 Kreimann EL, Morales FC, de Orbeta-Cruz J, Takahashi Y, Adams H, Liu TJ, McCrea PD and Georgescu MM: Cortical stabilization of beta-catenin contributes to NHERF1/EBP50 tumor suppressor function. Oncogene 26: 5290-5299, 2007.

17 Dai JL, Wang L, Sahin AA, Broemeling LD, Schutte M and Pan Y: NHERF $\left(\mathrm{Na}^{+} / \mathrm{H}^{+}\right.$exchanger regulatory factor $)$gene mutations in human breast cancer. Oncogene 23: 8681-8687, 2004.

18 Kalikin LM, Qu X, Frank TS, Caduff RF, Svoboda SM, Law DJ and Petty EM: Detailed deletion analysis of sporadic breast tumors defines an interstitial region of allelic loss on $17 \mathrm{q} 25$. Genes, chromosomes \& cancer 17: 64-68, 1996.

19 Kalikin LM, Frank TS, Svoboda-Newman SM, Wetzel JC, Cooney KA and Petty EM: A region of interstitial 17q25 allelic loss in ovarian tumors coincides with a defined region of loss in breast tumors. Oncogene 14: 1991-1994, 1997.

20 Mangia A, Partipilo G, Schirosi L, Saponaro C, Galetta D, Catino A, Scattone A and Simone G: Fine Needle Aspiration Cytology: A Tool to Study NHERF1 Expression as a Potential Marker of Aggressiveness in Lung Cancer. Mol Biotechnol 57: 549-557, 2015.

$21 \mathrm{Gu} \mathrm{Y,} \mathrm{Yu} \mathrm{H,} \mathrm{Hao} \mathrm{C,} \mathrm{Martin} \mathrm{TA,} \mathrm{Hargest} \mathrm{R,} \mathrm{He} \mathrm{J,} \mathrm{Cheng} \mathrm{S} \mathrm{and}$ Jiang WG: NHERF1 regulates the progression of colorectal cancer through the interplay with VEGFR2 pathway. Oncotarget 8: 7753-7765, 2017.

22 Park SJ, Choi YS, Lee S, Lee YJ, Hong S, Han S and Kim BC: BIX02189 inhibits TGF-betal-induced lung cancer cell metastasis by directly targeting TGF-beta type I receptor. Cancer letters 381: 314-322, 2016.

23 Lin G, Liu B, Meng Z, Liu Y, Li X, Wu X, Zhou Q and Xu K: MiR-26a enhances invasive capacity by suppressing GSK3beta in human lung cancer cells. Exp Cell Res 352: 364374, 2017.

24 Tsoukalas N, Aravantinou-Fatorou E, Tolia M, Giaginis C, Galanopoulos M, Kiakou M, Kostakis ID, Dana E, Vamvakaris I, Korogiannos A, Tsiambas E, Salemis N, Kyrgias G, Karameris A and Theocharis S: Epithelial-mesenchymal transition in non small-cell lung cancer. Anticancer Res 37: 1773-1778, 2017.

25 Thiery JP, Acloque H, Huang RY and Nieto MA: Epithelialmesenchymal transitions in development and disease. Cell 139: 871-890, 2009.

26 Cappellesso R, Marioni G, Crescenzi M, Giacomelli L, Guzzardo V, Mussato A, Staffieri A, Martini A, Blandamura S and Fassina A: The prognostic role of the epithelial-mesenchymal transition markers E-cadherin and Slug in laryngeal squamous cell carcinoma. Histopathology 67: 491-500, 2015. 
27 Ungefroren $\mathrm{H}$, Witte $\mathrm{D}$ and Lehnert $\mathrm{H}$ : The role of small GTPases of the Rho/Rac family in TGF-beta-induced EMT and cell motility in cancer. Dev Dyn, 2017. doi: 10.1002/dvdy.24505. [Epub ahead of print]

28 Chen L, Fu H, Luo Y, Chen L, Cheng R, Zhang N and Guo H: cPLA2alpha mediates TGF-beta-induced epithelial-mesenchymal transition in breast cancer through PI3k/Akt signaling. Cell Death Dis 8: e2728, 2017.

29 Abdulla T, Luna-Zurita L, de la Pompa JL, Schleich JM and Summers R: Epithelial to mesenchymal transition-the roles of cell morphology, labile adhesion and junctional coupling. Computer methods and programs in biomedicine 111: 435-446, 2013.

30 Thiery JP: Epithelial-mesenchymal transitions in tumour progression. Nat Rev Cancer 2: 442-454, 2002.

31 Karvar S, Suda J, Zhu L and Rockey DC: Distribution dynamics and functional importance of NHERF1 in regulation of Mrp-2 trafficking in hepatocytes. Am J Physiol Cell Physiol 307: C727$737,2014$.
32 Malfettone A, Silvestris N, Paradiso A, Mattioli E, Simone G and Mangia A: Overexpression of nuclear NHERF1 in advanced colorectal cancer: association with hypoxic microenvironment and tumor invasive phenotype. Exp Mol Pathol 92: 296-303, 2012.

33 Saponaro C, Malfettone A, Dell'Endice TS, Brunetti AE, Achimas-Cadariu P, Paradiso A and Mangia A: The prognostic value of the $\mathrm{Na}(+) / \mathrm{H}(+)$ exchanger regulatory factor 1 (NHERF1) protein in cancer. Cancer Biomark 14: 177-184, 2014.

Received May 19, 2017

Revised June 8, 2017

Accepted June 9, 2017 